\title{
ARTIGO
}

\section{NUBANK: UMA VISÃO EXPLORATÓRIA DO MODELO DE NEGÓCIOS DA STARTUP ${ }^{1}$}

\author{
João Paulo Nascimento da Silva ${ }^{2}$ \\ Álvaro Leonel de Oliveira Castro \\ Joel Yutaka Sugano \\ Cledison Carlos de Oliveira
}

\section{RESUMO}

Com o advento das tecnologias da informação e a crescente influência das fintechs, um tipo de startup voltada para o desenvolvimento de tecnologias e soluções financeiras, este artigo faz uso da netnografia como metodologia de pesquisa para estudo da Nubank, startup que desenvolve um modelo de negócios inovador. Com o objetivo de apresentar o modelo de proposta de valor da Nubank, este estudo apresenta a visão dos clientes usuários da empresa, de forma a contrastar o modelo real e o absorvido pelo mercado, sendo possível detectar que a empresa ainda mantém o mesmo padrão da proposta de valor inicial. Porém, critérios como Transparência e Desburocratização já são percebidos como falhos para a empresa.

Palavras-chave: Nubank. Modelo de negócios. Proposta de valor.

\section{INTRODUÇÃO}

Este artigo visa explorar, dentro da construção do Modelo de Negócios da Nubank, sua proposta de valor apresentada ao mercado e sua percepção pelo cliente. A Nubank é uma empresa de serviços financeiros online que tem como principal produto o cartão de crédito sem burocracia e livre de anuidade - sua principal ferramenta de diferenciação no mercado. Segundo o site da empresa, o objetivo desta é "acabar com a complexidade e devolver o controle da vida financeira para cada um", tendo ainda a própria definição como "uma startup que desenvolve soluções simples, seguras e $100 \%$ digitais para você ter o controle do seu

\footnotetext{
${ }^{1}$ SILVA, João Paulo Nascimento et al. Nubank: uma visão exploratória do modelo de negócios da startup. ForScience: revista científica do IFMG, Formiga, v. 6, n. 3, p. 00465, 2018.

${ }^{2}$ Autor para correspondência: João Paulo Nascimento da Silva, jpnsilvas@gmail.com.
} 
dinheiro literalmente nas suas mãos", denominando-se como um empresa contra a burocracia, a papelada, as agências e as centrais de atendimento ineficientes (NUBANK, 2017).

Iniciada em 2013 e, hoje, com mais de 8 milhões de solicitações do cartão (NUBANK, 2017), a empresa já recebeu aporte de capital de investidores como a Sequoia Capital, Kaszek Ventures, Tiger Global, QED, Founders Fund, e DST Globals (NUBANK, 2017), sendo considerada uma das Startups mais promissoras do mercado brasileiro.

Dessa forma, a startup desenvolveu um modelo de negócios inovador e contínuo, lançando recentemente seu programa de fidelidade, focado na retenção da base de clientes, e também novos produtos, como os serviços de contas correntes (NUBANK, 2017), tudo dentro da plataforma e modelo de negócios online.

Nessa perspectiva, este artigo busca compreender: como é a percepção da proposta de valor da Nubank pelos clientes do seu Modelo de Negócios de Inovação? Dessa forma, o objetivo deste artigo é realizar uma análise do modelo de negócios e da proposta de valor empregada pela Nubank. Sendo assim, com uma visão netnográfica dos clientes, é possível apresentar a forma como o modelo é percebido pelo mercado, na proposta apresentada por Osterwalder e Pigneur (2011), em busca de compreender se ela mantém o padrão de valor proposto.

\section{REFERENCIAL TEÓRICO}

Para este artigo, é preciso uma melhor compreensão sobre o conceito de fintech desenvolvido dentro da academia em que a empresa selecionada para este caso se enquadra, sendo necessário para o desenvolvimento do conceito de modelo de negócios da empresa em estudo.

Rosa et al. (2017), em seu estudo sobre práticas de gestão para cocriação de valor, apontam as fintechs como um fenômeno que tem revolucionado o mercado de startups ligadas ao setor financeiro. Dhar e Stein (2017) apontam que as fintechs são empresas que criam inovações do setor financeiro envolvendo modelos de negócios com tecnologia que podem facilitar a desintermediação ou revolucionar a forma como as empresas existentes criam e entregam produtos e serviços, como a proposta de valor da Nubank, empresa aqui estudada.

Minto, Voelkerling e Wulff (2017) afirmam que o setor de Fintechs compreende um grupo de provedores de inovações orientadas para a tecnologia, e alguns deles abrem novos mercados no setor financeiro, ou, ainda, oferecem novas soluções para substituir ou aumentar produtos ou serviços já oferecidos. Dessa forma, os autores declaram que as mudanças do 
setor estão sendo rápidas e com inovadores modelos de negócios, de maneira a criar ferramentas automatizadas para facilitar o acesso do mercado (MINTO; VOELKERLING; WULFF, 2017).

Para tanto, uma inovação de modelo de negócios trata da criação de novas proposições de valor, dos sistemas relacionados à entrega e captura de valor, de forma a gerar valor econômico superior. Dessa forma, a criação de um modelo de negócio consiste em uma proposta de valor, como produtos e/ou serviços que uma empresa oferece para seus clientes; um sistema de criação e entrega de valor, na forma de atividades, processos e recursos através dos quais a empresa entrega a proposta de valor e alcança vantagem competitiva; e na captura de valor, como a empresa gera receitas e lucros com a entrega da proposta (RICHARDSON, 2008).

Nesse sentido, Teece (2010) aponta que um modelo de negócio descreve o design ou a arquitetura de como o valor é criado, entregue e capturado por uma organização. Baldassarre et al. (2017) argumentam que a ferramenta de mapeamento de valor seria beneficiada por ser integrada com princípios da inovação orientada por usuários, de forma a abordar a importância da criatividade, da experimentação e da interação como uma maneira de atender às necessidades dos usuários, ao mesmo tempo em que cria oportunidades lucrativas de negócios.

Dada esta importância aos modelos de negócios, faz-se necessário entender o padrão apresentado por Osterwalder (2002), em que o modelo de negócios é descrito como uma "lógica de um sistema de negócios para criar valor". Nesta mesma pesquisa, Osterwalder (2002) mostra uma abordagem de modelos de negócios para o padrão de comércio eletrônico, como uma base de ferramentas que permitam a compreensão, o compartilhamento, a comunicação, a mudança, a mediação e a simulação dos modelos a serem implantados.

Osterwalder e Pigneur (2014) apresentam ainda um design de proposta de valor posterior à concepção do modelo de negócios, no qual é possível captar uma maior aproximação da proposta criada pela empresa e da entendida pelo cliente - a qual será utilizada por este artigo para compreensão do segmento de mercado do caso em estudo. 


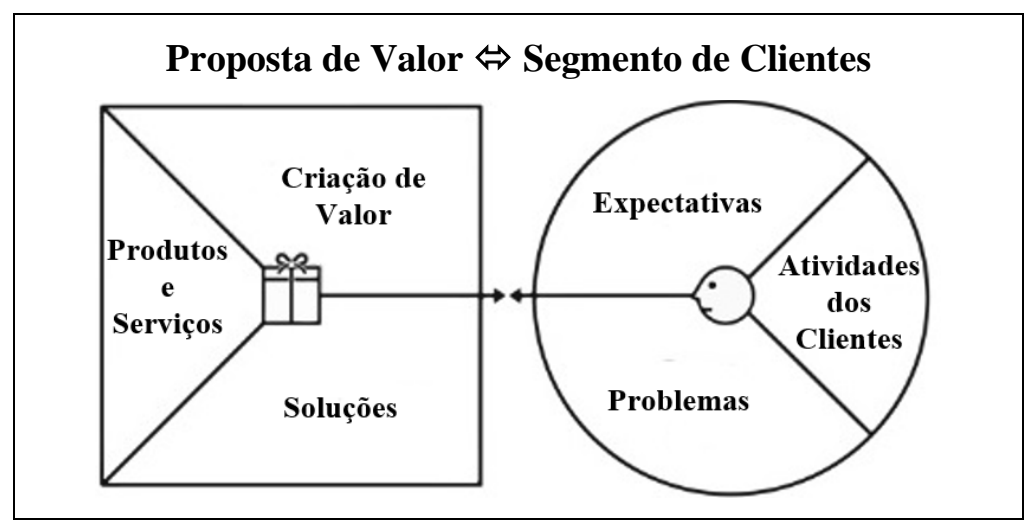

Figura 1 - Design de Proposta de Valor

Fonte: Adaptado de Osterwalder e Pigneur (2014).

A proposta de valor pode ser entendida conforme o Quadro 1, abaixo:

\begin{tabular}{|l|lr|}
\hline \multicolumn{1}{|c|}{ Proposta de Valor } & \multicolumn{1}{|c|}{ Segmento de Clientes } \\
\hline $\begin{array}{l}\text { Criação de Valor - criar uma nova forma de } \\
\text { ganhos/valor para um determinado perfil de } \\
\text { cliente }\end{array}$ & $\begin{array}{l}\text { Expectativas (Ganhos) - concentrar nas } \\
\text { expectativas de ganho essenciais não realizadas } \\
\text { por clientes }\end{array}$ \\
\hline $\begin{array}{l}\text { Produtos e Serviços - imaginar um novo produto } \\
\text { ou serviço }\end{array}$ & $\begin{array}{l}\text { Atividades dos Clientes - descobrir as } \\
\text { necessidades insatisfeitas do cliente }\end{array}$ \\
\hline $\begin{array}{l}\text { Soluções (Analgésicos) - criar uma solução para } \\
\text { um determinado perfil de cliente }\end{array}$ & $\begin{array}{l}\text { Problemas (Dores) - resolver a dor mais extrema } \\
\text { e não resolvida de seus clientes }\end{array}$ \\
\hline
\end{tabular}

Quadro 1 - Proposta de Valor e Segmentação de Clientes

Fonte: Adaptado de Osterwalder e Pigneur (2014).

O design da proposta de valor apresentado consiste em realizar a observação do segmento de clientes e do mercado, de modo a criar valor com as soluções desenhadas (OSTERWALDER; PIGNEUR, 2014). Para Osterwalder e Pigneur (2014), o valor é criado por meio da junção das atividades do segmento/mercado com as atividades desenvolvidas para tal solução, de forma que o design da proposta de valor vise contemplar as soluções para os principais problemas, sendo elas produtos, serviços ou modelos de negócios.

\section{MÉTODOS E PROCEDIMENTOS}

Este artigo foi realizado com base na metodologia de pesquisa Netnográfica que, segundo Kozinets (2002), baseia-se na aplicação de uma pesquisa etnográfica realizada na internet, valendo-se do acesso a comunidades online, de forma a compreender informações sobre simbolismo, significados e padrões de consumo desses grupos de consumidores, o que, nesse caso, se aplica diretamente aos consumidores/usuários do cartão de crédito Nubank. Segundo o autor, os consumidores fazem escolhas cada vez mais voltadas para a comunicação 
mediada por computador, seja através de pesquisas ou de comunidades virtuais, influenciando aspectos de seu comportamento como consumidor (KOZINETS, 2002, 2010).

Para Kozinets (2002), as comunidades online são contextos em que os consumidores frequentemente participam de discussões, e a Netnografia estuda as comunicações nas diversas formas de contatos online, seja com entradas em fóruns, grupos virtuais em redes sociais, páginas da web, listas de mensagens em aplicativos, salas de bate-papo, entre outros meios (KOZINETS, 2002).

Além disso, as informações para construção da Proposta de Valor da Companhia foram coletadas diretamente do site institucional da Nubank. Os dados sobre a recepção de feedback, as informações, as sugestões e as dúvidas dos usuários do aplicativo da Nubank foram coletados na Plataforma Google Play, utilizando o sistema operacional Android.

A página oficial da Nubank, na rede social Facebook, foi utilizada para coletar as comunicações diretas da empresa com seus usuários, tais como as postagens de divulgação e informação sobre os seus produtos e novidades. Já a comunidade online, sediada na mesma rede, onde há grande interação entre os mais de 120 mil usuários da Nubank, foi utilizada para responder as perguntas sobre as preferências em relação aos produtos e serviços da empresa, além de serem verificadas outras interações do grupo, de modo a fomentar a discussão sobre o tema.

A coleta de dados ocorreu entre novembro de 2017 e janeiro de 2018. Assim, esta pesquisa contemplou uma etapa inicial, onde foi desenvolvida a proposta de valor da Nubank, com base nas informações contidas em seu site e páginas oficiais. Posteriormente, em uma segunda etapa, levantou-se a proposta de valor da empresa na visão dos usuários da plataforma online, por meio da pesquisa netnográfica (KOZINETS, 2002), construindo-se, assim, a proposta de valor efetivamente recebida pelos clientes da Nubank.

Por fim, compararam-se as duas propostas de valores. Dessa forma, a análise dos dados foi realizada com base em observações do pesquisador e no discurso textual coletado, com a finalidade de interpretar as percepções da proposta de valor da empresa, sob a ótica de seus consumidores.

\section{ANÁLISE DO CASO NUBANK}

A Nubank (https://www.nubank.com.br/) é uma startup com base em solução de problemas financeiros. Conforme definição do próprio site, "uma startup que desenvolve soluções simples, seguras e 100\% digitais", com o objetivo de devolver o controle financeiro 
para o usuário (NUBANK, 2017), sem a necessidade de complexas transações do mercado tradicional.

Com a intenção de aplicar soluções simples, atividades de marketing que buscam cativar os clientes e com a oferta de tecnologia e design para resolver os problemas, a Nubank desafia o modelo de negócios tradicional das instituições bancárias. Inicialmente, com o modelo de negócios de cartões de crédito, reforçado pelo programa de recompensas; e, mais recentemente, com o lançamento do plano de contas correntes, tudo presente na plataforma online.

A empresa desenvolveu um modelo de negócios de contínua inovação, vindo a lançar recentemente seu programa de fidelidade, focado na retenção da base de clientes e no lançamento de novos produtos, como os serviços de contas correntes (NUBANK, 2017), concentrando o relacionamento com o cliente, o seu contato, o design, a tecnologia e o modelo de negócios da empresa - tudo sob uma única plataforma.

A Nubank apresenta, em seus pilares, características que direcionam para o uso da tecnologia como forma de facilitar as transações bancárias, com o desenvolvimento próprio de linguagens funcionais, visando à melhoria dos produtos e do design. Em relação à diminuição da complexidade comum aos serviços financeiros, a empresa oferece uma melhor experiência, de forma a facilitar acessos e resolução de problemas dos clientes (NUBANK, 2017).

Assim, é possível apresentar as principais características da Proposta de Valor da Nubank, presentes em seu site, na tabela abaixo, conforme a proposta de Osterwalder e Pigneur (2014).

\begin{tabular}{|c|c|}
\hline \begin{tabular}{|l|} 
Proposta de Valor \\
\end{tabular} & \begin{tabular}{|c|} 
Segmento de Clientes \\
\end{tabular} \\
\hline $\begin{array}{l}\text { Criação de Valor } \\
\text { - Usabilidade/Simplicidade e Transparência } \\
\text { - Cartão de Crédito 100\% Digital, sem } \\
\text { anuidade e sem tarifas; } \\
\text { - Design. }\end{array}$ & $\begin{array}{l}\text { Expectativas (Ganhos) } \\
\text { - Serviços financeiros complexos; } \\
\text { - Serviços bancários ineficientes; } \\
\text { - Agências de atendimento; } \\
\text { - Distanciamento do mercado financeiro em } \\
\text { relação ao cliente. }\end{array}$ \\
\hline $\begin{array}{l}\text { Produtos e Serviços } \\
\text { - Gerenciamento de compras, de limite, da } \\
\text { fatura via Smartphone e } \\
\text { Bloqueio/Desbloqueio do Cartão; } \\
\text { - Desconto por antecipação de parcelas } \\
\text { (2016); } \\
\text { - Programa de recompensas (2017); } \\
\text { - Conta corrente online sem anuidade (2017). }\end{array}$ & $\begin{array}{l}\text { Atividades dos Clientes } \\
\text { • Gerenciamento das atividades do cartão; } \\
\text { • Relação com as agências. }\end{array}$ \\
\hline $\begin{array}{l}\text { Soluções (Analgésicos) } \\
\text { - Sem burocracia para liberação de crédito; } \\
\text { - Alta qualidade de atendimento (Atendimento }\end{array}$ & $\begin{array}{l}\text { Problemas (dores do mercado tradicional) } \\
\text { - Programas de recompensas que expiram; } \\
\text { - Negociações bancárias burocráticas; }\end{array}$ \\
\hline
\end{tabular}




\begin{tabular}{|l|l|}
\hline $\begin{array}{l}\text { próprio e facilitado via telefone, aplicativo, } \\
\text { e-mail ou redes sociais); }\end{array}$ & $\begin{array}{l}\text { - Dificuldade de liberação de crédito (cartão); } \\
\text { - Taxas de juros abaixo do mercado. }\end{array}$ \\
& $\begin{array}{l}\text { - Bificuldade de contato dos clientes com as } \\
\text { - Baixa qualidade do atendimento; } \\
\text { - Elevadas taxas de juros; } \\
\text { - Elevadas taxas de anuidade. }\end{array}$ \\
\hline
\end{tabular}

Quadro 2 - Proposta de Valor da Nubank

Fonte: Dados da Pesquisa (2017).

Conclusão.

No Quadro 2, com o intuito de melhorar a compreensão sobre a pesquisa, as necessidades, os desejos e as demandas por melhorias no mercado tradicional foram apresentadas no campo Segmento de Clientes, enquanto as alterações do modelo tradicional propostas pela Nubank para solucionar tais demandas foram apresentadas no campo de Proposta de Valor.

Dessa forma, a etapa seguinte da pesquisa visa apresentar a Proposta de Valor da Nubank que é percebida pelos usuários online, de forma a contrastar com a proposta apresentada pela própria empresa.

\section{ANÁLISE DA PROPOSTA DE VALOR DA NUBANK}

A análise da Proposta de Valor da Nubank será apresentada com base na tabela acima, nos âmbitos de Criação de Valor, Produtos e Serviços e Soluções, de forma a contrastar a proposta com a percepção do mercado.

Dentre as propostas para Criação de Valor da Nubank no mercado, a Usabilidade/Simplicidade e a Transparência são apontadas pela própria empresa como características de seu produto, "simplificando o controle da vida dos usuários" (NUBANK, 2017), sendo atributos da proposta de valor muito absorvidos pelos usuários.

Sendo assim, um usuário do Google Play noticiou como "Perfeito. Usabilidade e transparência no serviço. Nubank será o banco do futuro (conta corrente, cartão de débito e cheque especial)" (jan/2018), já se antecipando ao fato de os possíveis próximos produtos terem o mesmo padrão de qualidade dos atuais. Em uma postagem na página oficial da Nubank no Facebook (nov/2017), agradecendo aos usuários por participarem de um vídeo sobre a "revolução" ocasionada pelo aplicativo, um usuário comentou dizendo "Vocês são demais! Não existe uma palavra só para definir, é tudo que o consumidor precisa simplificado e direto, de um jeito honesto e rápido, sem burocracias! Continuem assim que 
vão longe!", apontando para a satisfação em relação às facilidades que o modelo Nubank traz em relação ao modelo tradicional.

Dois usuários da comunidade online instalada na rede social Facebook comentaram em uma postagem criada sobre o que mais os atrai em relação ao produto Nubank (nov/2017), ressaltando a "facilidade no uso e controle de gastos" que o aplicativo da empresa proporciona e a "facilidade de acesso às informações (fatura/ vencimento/valores), o melhor aplicativo de cartão", realçando o valor da empresa sobre os critérios de Usabilidade e Simplicidade.

As interações sobre a transparência da empresa em relação às suas transações foram menores. Porém, vale ressaltar o posicionamento de um usuário em resposta à postagem na rede Facebook sobre a liberdade proporcionada pela Nubank:

\footnotetext{
Eu já tive cartão um tempo atrás e só tive desgosto, na verdade peguei foi trauma disto, depois de alguns amigos me falarem sobre o Nubank resolvi pesquisar mais a fundo e vi que realmente tudo o que falavam estava correto, uma empresa totalmente transparente no que oferece, então eu mesmo resolvi me cadastrar sem nenhum tipo de convite, e achei que iria demorar muitos dias, porém a minha aprovação foi em apenas... 4:15min!!!! Nem dá para acreditar que foi tão rápido $e$ tão simples!!!"'(dez/2017)
}

Apesar do relato completo valorizando a transparência da companhia, a maioria das interações faz menção à facilidade e à simplicidade de utilização dos produtos Nubank.

O Cartão de Crédito $100 \%$ digital sem anuidade e sem tarifas é o principal produto de apresentação da Nubank, sendo o grande diferencial inicial dos usuários em relação ao mercado tradicional. Em uma enquete realizada na comunidade online do Facebook, dentre as opções de Proposta de Valor descritas na Tabela 2, a isenção de anuidades e tarifas foi a mais selecionada pelos usuários. Porém, tanto na comunidade online da página oficial no Facebook quanto na do Google Play, não foram encontrados comentários que revelassem a importância da isenção de anuidades e tarifas. No entanto, como este é o produto que define a criação da Nubank, talvez ela já tenha sido absorvida pelos usuários como principal valor e característica de existência da empresa.

A proposta de valor em Design da Nubank está muito relacionada à facilidade de cadastro e de uso do aplicativo. Porém, é bastante absorvida pelos usuários a partir da cor roxa adotada pela marca, sendo encontrada em várias postagens aqui pesquisadas com a hashtag \#roxinho, fazendo referência à cor do cartão.

Quanto às características do design que reforçam a percepção dos usuários, um comentário encontrado na plataforma Google Play (jan/2018) diz “Adorei o app, fácil de usar, ForSci.: r. cient. IFMG, Formiga, v. 6, n. 3, e 00465, jul./dez. 2018 
tem um design belíssimo e simplifica a vida do usuário. Desde o momento do cadastro até o acompanhamento via App, é descomplicado e transparente", reforçando o posicionamento acima descrito. Outro usuário da página oficial no Facebook, em resposta a uma postagem sobre o agradecimento aos usuários pela participação e feedback em relação aos produtos e serviços (nov/2017), aponta: “App extremamente funcional, facilidade para pagar, adiantar as coisas e etc.", fazendo menção à facilidade de utilizar o aplicativo e seus serviços.

Como segundo critério presente na proposta de valor, dentre os Produtos e Serviços criados pela Nubank, com exceção do produto inicial, o cartão de crédito, discutido acima, o Gerenciamento de Compras, de limite, da fatura via Smartphone e Bloqueio/Desbloqueio do Cartão são pontos de grande relevância. O gerenciamento é um dos pontos mais apreciados pelos usuários da Nubank. Essa proposta de valor é traduzida por alguns usuários como a liberdade em relação aos padrões tradicionais de outros cartões. Um usuário da Plataforma Google Play (jan/2018) postou que o produto é "Disparado o melhor serviço de crédito no mercado, total gestão pelo app, constante melhoria por parte do Nubank!". Outro usuário da mesma plataforma apontou que:

O único que realmente pode ser chamado de disruptivo, de fato. Excelente em todos os aspectos! $O$ único verdadeiramente digital, com a possibilidade de gerenciamento de despesas pelo próprio app ou de sincronizar com outros aplicativos financeiros; com atendimento impecável, rápido e preciso! Torço para que sigam dessa forma, crescendo com essa qualidade! (dez/2017).

Outro usuário da plataforma Google Play (dez/2017) chamou a atenção para a facilidade de gerenciamento da plataforma, em relação à sua opção de bloqueio e desbloqueio: “Conteúdo fácil e prático. Pode até adiantar a fatura do cartão. Mexer no limite e acompanhar em tempo real as compras detalhadas. Pode-se bloquear ou liberar o cartão em caso de perda". Em resposta a uma postagem no Facebook sobre os produtos e serviços da Nubank (nov/2017), um usuário apresentou o produto como "Melhor cartão de crédito, com certeza! Não preciso mais de caderninho para guardar todas as prestações, porque fica tudo no aplicativo. E você acabou de comprar já entra no aplicativo todas as parcelas... uma maravilha. Estou 'in love' com meu roxinho".

Em relação à comunidade online, esse foi o ponto com maior quantidade de interações quanto aos critérios de valor da Nubank. Um usuário da comunidade relatou que:

Eu gosto de muitas coisas.... Mas destaco a função de colocar \# e editar as compras... Isso me ajuda demais da conta, pois eu consigo separar tudo na fatura, as compras que são de outras pessoas, consigo ver o que eu gasto nos mesmos locais todos os meses, organizo as compras que eu faço no trabalho, as que eu faço 
em casa, as que faço com amigos, na \# e na edição também marco as compras que já recebi ou que já depositei o dinheiro delas pra pagar depois... Enfim, essa função de colocar \# e de editar o nome das compras eu uso demais e acho essencial pra minha organização!!! (nov/2017).

Dessa forma, esta pode ser considerada uma das propostas de valor da Nubank que mais traduzem a realidade dos usuários em relação à possibilidade de organização que não é própria dos modelos tradicionais.

Quanto ao serviço de desconto por antecipação de parcelas, lançado em 2016, apesar da novidade, não foi motivador para a frequência de uso dos cartões. Sendo assim, como não fez parte dos produtos pioneiros entregues pela Nubank em seu lançamento, foi aceito mais como uma inovação incremental, uma forma de ampliar o valor, mas não com a mesma receptividade dos produtos iniciais.

Um usuário respondeu a uma postagem na rede social Facebook referente à liberdade proporcionada pela Nubank (dez/2017) relatando que “De 2013 a 2017, continua sendo o melhor dos melhores cartões com anuidade zero no mercado, poder fazer pagamentos avulsos sempre que quiser, antecipar parcelas e ainda ganhar descontos, anuidade zero, aplicativo supermoderno e ágil e útil", ressaltando estes e outros serviços prestados pela Nubank, mas dando maior importância à anuidade zero e menor relevância à antecipação de parcelas com descontos, juntamente a outros serviços prestados.

O Programa de Recompensas parece ser direcionado da mesma forma que o serviço de antecipação de parcelas; os clientes tomaram como um incremento aos serviços prestados. Na postagem sobre produtos e serviços, na rede social Facebook (nov/2017), um usuário respondeu: "Já faz um bom tempo que tenho o cartão, e o serviço é realmente sensacional! Ontem já iniciei minha NuConta e parece muito promissora também. Quando pediram um sistema de recompensas, apresentaram um que realmente é diferenciado".

Apesar da aparente boa recepção do programa supracitado em relação aos programas apresentados no mercado, ele continua como incremento aos produtos iniciais. Talvez esse fato seja explicado pela taxa cobrada para adesão ao programa de recompensas, que anula a tarifa gratuita do cartão, tida pelos usuários como direito próprio.

A conta corrente online sem anuidade, apesar de não ser lançada como produto inicial da Nubank, foi tida como outra grande inovação da empresa. Mesmo sendo um produto ainda em fase de testes, é um dos maiores motivadores de comentários nas bases pesquisadas, tanto por clientes interessados em realizar os testes quanto por aqueles afoitos por saber sobre seu lançamento definitivo. Em uma postagem na rede social Facebook intitulada "365 razões para não ir ao banco" (dez/2017), a própria Nubank respondia a 
comentários com a hashtag "\#thefutureispurple", dando um indicativo das possibilidades de serviços futuros aos usuários.

Em resposta à postagem sobre os produtos e serviços da Nubank (nov/2017), um usuário afirma que "Aguardando a nuconta, que já tá demorando, se for bom igual ao cartão, vou abandonar os bancos, obrigado a todos que fazem parte dessa revolução". Outro usuário da Plataforma Google Play postou que "Só aguando a NuConta para testar, e se tudo der certo, que ela evolua para uma conta corrente completa e eu possa abandonar meu banco velho de vez!" (jan/2018), sinalizando entusiasmo em relação à chegada do produto.

Para as Soluções (Analgésicos), o primeiro critério apontado foi a propaganda do cartão como sem burocracia para liberação de crédito. Tida como um dos carros-chefes do produto Nubank e um dos valores mais reconhecidos pelos usuários, a falta de burocracia se tornou um dos grandes diferenciais entre a Nubank e as instituições financeiras tradicionais.

Um usuário da plataforma Google Play relata que "O Nubank oferece um serviço desburocratizado e com um app bem intuitivo, sem contar a excelente relação com o cliente" (jan/2018). Outro usuário da mesma plataforma também relata que "Chega a ser surreal ver como algo tão simples funciona muito bem e facilita a vida de qualquer pessoa. A comodidade de ter tudo na palma da sua mão é fantástica; chega de se estressar com filas em bancos e atendimentos péssimos" (dez/2017), apoiando as características de desburocratização dos processos na Nubank.

Em resposta a uma postagem sobre 1.000 .000 de likes na página do Facebook (nov/2017), um usuário parabeniza dizendo que "vocês já dão de infinito a zero nos demais bancos, sua política, sem filas, sem tarifas, sem stress". Outro usuário menciona que:

[...] quando li sobre a ideia achei revolucionário, sem anuidade, atendimento totalmente digital, cópia de documentos pessoais por foto, assinatura na tela? Meu cartão foi aprovado em menos de 15 minutos, com um limite que nenhum banco nunca tinha me oferecido (nov/2017).

Dessa forma, é possível compreender que a política de desburocratização do produto Nubank é também um de seus valores mais disseminados entre os usuários. No entanto, da mesma forma que é um valor, ele pode estar começando a se tornar um entrave para a Nubank. A companhia não divulga a quantidade de usuários do cartão atualmente; porém, aponta em seu site que 8 milhões de pessoas já solicitaram o cartão, e a lista de espera está superior a 500 mil pessoas (NUBANK, 2017). 
Dentro das plataformas pesquisadas, há um constante questionamento dos usuários pela demora em relação às respostas, que pode durar até 6 meses, e pelas respostas negativas, sem justificativas. O número de pretendentes a usuários do cartão Nubank que se relacionam nas redes de contato da empresa para reclamações por demora ou negativas é grande, assim como os baixos limites ofertados e as recusas de aumento. Durante as pesquisas, foi possível observar que a empresa prega uma desburocratização, que ocorre no cadastro do aplicativo e no tratamento em relação a informações ou problemas, mas que se torna um ponto negativo para os pretendentes ao cartão e ao aumento de limites. Dessa forma, este é um dos pontos que a Nubank aponta com sendo forte em sua proposta de valor; no entanto, traz características negativas em relação à base de clientes.

A qualidade do atendimento é outro critério de valor da proposta da Nubank, tido como um dos maiores diferenciais em relação às instituições financeiras tradicionais. Segundo usuários da Plataforma Google Play, "Nunca gostei de cartão de crédito, mas quando conheci o Nubank, nossa! É demais o atendimento, eles se preocupam com você e uma família, hoje não me imagino sem o Nu" (jan/2018); “ Pedi para alterarem o número da minha residência para a entrega do cartão e fui respondido em $3 \mathrm{~min}$. Agora me diz se o Itaú, Santander, Caixa, BB fariam isso?” (jan/2018); “Cartão perfeito, atendimento perfeito, tanto pelo e-mail ou pelo 0800, a atendente me atendeu com todo carinho e respeito... adorei" (dez/2017).

Nas postagens via Facebook, o engajamento é ainda maior. Em uma postagem sobre os produtos e serviços da Nubank (nov/2017), um usuário relatou que "A forma como vocês nos tratam pelo telefone ou pelo chat é maravilhoso. É como se eu estivesse conversando com um amigo por telefone, isso ajuda demais, sem dor de cabeça e sempre disposto a ajudar. Sou mais feliz com meu \#Nu". Outro usuário destaca que "quanta energia positiva, não ler reclamações me dá uma felicidade inexplicável. Em se tratando de banco, isso é realmente surreal. Parabéns, NUBANK, vocês identificaram os problemas e fizeram a diferença".

Basicamente, as únicas reclamações que aparecem na fanpage da empresa são relacionadas a baixos limites e a recusas aos pedidos de adesão do cartão. Quando respondidas pela Nubank, elas são creditadas ao grande número de solicitações, pedindo aos pretendentes para que realizem uma nova tentativa em alguns meses, ou, no caso de aumento de limites, indicando oportunidades para melhorar as chances do usuário. Estas duas reclamações, que aparecem constantemente em todas as plataformas pesquisadas, podem ser um indício do aumento da burocracia da instituição, mesmo que devido ao volume de solicitações e análises, mas como ponto negativo dentro dos pilares das tradicionais que a empresa se propõe a dissolver. 
As taxas de juros abaixo do mercado pregadas pela Nubank, propostas inicialmente como taxa fixa, hoje variam de acordo com o usuário. Porém, a mudança parece não afetar parte dos usuários, visto que a proposta de valor inicial com relação à taxa de juros permanece como sendo de juros mais baixos que os do mercado tradicional.

Um usuário da plataforma Google Play relata que "Sempre quis um cartão, mas tinha medo dos juros e anuidades e com a Nubank não tenho medo nem um" (jan/2018); e outro diz ainda que o "Atendimento super-rápido e moldado para o cliente, sem complicações ou taxas abusivas" (dez/2017), ambos reforçando a diferença dos juros em relação ao mercado tradicional. Na postagem no Facebook sobre os produtos e serviços da Nubank (dez/2017), um usuário respondeu que "quando achei que não tinha mais como resolver problemas com o banco, como limite e taxas absurdas, o Nubank apareceu e descomplicou tudo... melhor experiência... indico para todos". Dessa forma, é possível compreender que o entendimento de grande parte dos usuários do cartão Nubank é de que a empresa emprega taxas de juros inferiores aos do mercado, como um grande diferencial aos bancos tradicionais.

Outros dois critérios de valor que foram observados na pesquisa e que devem ser apontados são a Inovação e a Experiência do consumidor. Os usuários relatam que tais características são um valor diferencial entre a Nubank e os bancos tradicionais.

Quanto à inovação, o cartão de crédito sem anuidade foi tomado pelos usuários como uma inovação do mercado - fato que também ocorreu com as contas correntes online. Em uma postagem no Facebook sobre os produtos e serviços da Nubank (dez/2017), um usuário respondeu à postagem comentando que "Chegou com inovação e modernidade em seus serviços, mostrou que é possível oferecer um produto de excelência em qualidade". Já outro usuário da Plataforma Google Play (dez/2017) relatou: "Um jeito inovador e simples de gerenciar os gastos com cartão, adeus cartões e bancos tradicionais...". Dessa forma, é possível entender que o valor criado pela imagem de inovação também atrai os usuários para o produto Nubank - fato iniciado pelo Cartão e agora continuado pela conta corrente online.

A experiência do consumidor é outra característica de valor que é ressaltada pelos usuários nas mídias pesquisadas. Alguns usuários da plataforma Google Play apontam para essa proposta de experiência: "Perfeito. A experiência é ótima, a agilidade e transparência te deixa seguro das despesas e possíveis compras. É uma instituição que só merece elogios" (jan/2018); "Estou extremamente satisfeito com os serviços prestados pelo App, tanto do cartão quanto da NuConta. A rapidez de vocês é absurda!" (dez/2017); e "O Nu é simplesmente sensacional. Aquele serviço feito para atender as necessidades dos clientes de forma prática e super fácil. Por mais serviços como o da Nubank!'” (dez/2017). 
Há relatos de satisfação dos clientes que só podem ser provocados pela experiência positiva em relação à utilização do cartão. Um usuário, em resposta a uma postagem sobre a liberdade proporcionada pela Nubank (dez/2017), comenta que "hoje eu vejo que eu não sou apenas mais um cliente, vejo que sou especial, que participo de um grupo de elite aonde todos os clientes são a nata do mercado de hoje". Em outra postagem sobre 365 razões para não ir ao banco (dez/2017), um usuário responde que "Em meio a muitas situações em que muitas empresas, organizações e etc. estão lesando o consumidor ai vem o \#Nubank e mostra um cenário diferente, que se preza igualdade e respeito! ". Respondendo à postagem sobre produtos e serviços da Nubank (nov/2017), um usuário comenta que "Sabem o que é "o mais incrível" da Nubank? Seus usuários são parecidos com os da Apple. São apaixonados pela marca, pela empresa. Querem muito que ela prospere e seja cada dia melhor! E sinto que é assim que vocês têm sido".

Assim, é possível perceber que os critérios de inovação e experiência do consumidor também estão relacionados à proposta de valor da Nubank, não como pilares, mas como desenvolvimento constante das atividades da empresa.

\section{CONSIDERAÇÕES FINAIS}

A proposta deste artigo para ampliar o conhecimento sobre a proposta de valor da Nubank que é recebida por seus clientes, dentro do seu Modelo de Negócios de Inovação (OSTERWALDER; PIGNEUR, 2014), aponta para o desenvolvimento de práticas constantes de inovação da companhia. Porém, nem todas são recebidas pelo público consumidor da mesma forma.

Quanto à proposta de Criação de Valor, os usuários recebem muito bem as características de Usabilidade e Simplicidade das atividades e do aplicativo Nubank. No entanto, prega-se o princípio de Transparência, que, aparentemente, não tem a mesma recepção por parte do consumidor. O Cartão de Crédito totalmente digital e sem anuidades ou tarifas, que é o produto inicial e o motivo de existência da Nubank, parece ter sido absorvido pelos usuários como princípio de existência da empresa, e, mesmo não tendo sido exaltado como outras características desta, é o principal motivo que os atrai. O design é outra característica que chama muito a atenção dos usuários. A cor roxa foi tomada como característica principal do produto e seu reflexo nas redes sociais, reforçando o apelo da marca. As características de Design em relação ao aplicativo são mais bem absorvidas com relação a sua facilidade de uso diário e para o cadastro de novos usuários. 
$\mathrm{Na}$ parte de produtos e serviços, foram considerados aqueles posteriores ao produto inicial, o cartão de crédito. Portanto, os demais valores giram, principalmente, em torno do gerenciamento de compras, de limite e de fatura, que são proporcionados pelo aplicativo via Smartphone, e da ferramenta de bloqueio e desbloqueio do cartão, considerada de grande utilidade por todos os usuários que interagiram sobre o tema, como parte da orientação para o usuário, proposta por Teece (2010). Quanto à ferramenta de desconto por antecipação de parcela e ao programa de recompensas, que foram lançados recentemente, parecem ter sido tomados pelos usuários como um incremente do produto principal da Nubank, e não como uma ferramenta de inovação em si. Ressalta-se que muitos usuários apontam para o programa de recompensas como diferenciado do mercado tradicional, mas ele ainda não é tomado como grande inovação. A conta corrente online, por outro lado, é tida como a grande inovação da Nubank após o cartão de crédito, causando grande alvoroço entre os usuários da comunidade online e das páginas oficiais da companhia. Com o modelo já absorvido pelos usuários do mercado (MINTO; VOELKERLING; WULFF, 2017), é possível perceber que os usuários creditaram, antes mesmo do lançamento oficial da conta corrente, os mesmos valores do cartão de crédito à conta, como uma característica da própria Nubank.

Em último passo, as Soluções propostas pela Nubank ressaltam suas características frente aos usuários, sendo que a desburocratização pregada pela empresa para acesso ao cartão já não é mais clara entre eles. A grande quantidade de pretendentes a usuários que estão insatisfeitos em relação às negativas sem explicação, nas tentativas de adesão ao produto, assim como as negativas também sem explicação, para o não aumento de limite de usuários do produto, deixam falha a característica da desburocratização. A Nubank aponta para uma fila de espera de mais de 500 mil pretendentes ao Cartão Nubank, que podem esperar até 6 meses por uma resposta (NUBANK, 2017), o que explica o fato de que o processo começou a se tornar burocrático. A liberação de documentação e outros pontos, que são parte do procedimento inovador da Nubank, estão sendo prejudicados pela burocracia para adesão e aumento de limite, considerada por muitos usuários como principal fator de desvalorização do produto.

Os demais pontos das Soluções da Proposta de Valor são muito positivos para a Companhia. A alta qualidade do atendimento é visível, sendo apontada por muitos usuários como o maior diferencial da Nubank em relação ao mercado tradicional. As taxas de juros, mesmo tendo sido aumentadas para alguns usuários do cartão, talvez sejam outro indício do aumento da burocracia na Nubank, mas que ainda não foi percebido pelos usuários como desvantajoso, mantendo, assim, a característica de taxas de juros abaixo do mercado. 
Dessa forma, é possível compreender que os produtos e características do desconto por antecipação de parcela e do programa de recompensas não foram assumidos pelos usuários com o mesmo valor do produto inicial - o Cartão Nubank sem anuidade - mas foram percebidos na chegada da conta corrente online. E, talvez, o principal ponto de desavença da proposta de valor da Nubank seja a proposta de desburocratização, que começa a sofrer com o crescimento da empresa e a grande quantidade de solicitações para adesão ao produto e aos aumentos de limite.

Este estudo se mostra importante para melhor compreensão da dinâmica de valor da proposta de uma empresa e da absorção de valor recebida pelo mercado. A contribuição gerencial deste artigo também aponta para a necessidade de acompanhamento entre a proposta inicial de valor de um negócio e o crescimento da empresa, podendo ser um entrave para que se consiga manter a proposta. Como sugestão para estudos futuros, propõe-se um estudo quantitativo para explorar as bases de valor da empresa em relação aos seus produtos e usuários, a fim de melhor compreender este desenvolvimento, assim como estudos para uma melhor análise do padrão de modelo de inovação de negócios da Nubank e sua plataforma de negócios.

\title{
NUBANK: AN EXPLORATORY VIEW OF THE STARTUP BUSINESS MODEL
}

\begin{abstract}
With the advent of information technologies and the influence of fintechs, a type of startup focused on the development of technologies and solutions, this is an example of netnography methodology for the development of technology, startup that develops an innovative business model. With the objective of presenting the Nubank's model of reference value proposal, the market test, real model registration and market consumption, it being possible to detect a company still with the same standard of the proposal of initial value. However, criteria as Transparency and Reduction of Bureaucracy are already perceived as flawed for a company.
\end{abstract}

Keywords: Nubank. Business model. Value proposition.

\section{REFERÊNCIAS}

BALDASSARRE, Brian et al. Bridging sustainable business model innovation and userdriven innovation: A process for sustainable value proposition design. Journal of cleaner production, v. 147, p. 175-186, 2017.

DA ROSA, Simone Carvalho et al. Management practices that combine value cocreation and user experience: An analysis of the Nubank startup in the Brazilian market. Revista de gestão, finanças e contabilidade, v. 7, n. 2, p. 22-43, 2017. 
DHAR, Vasant; STEIN, Roger M. Economic and business dimensions: finTech platforms and strategy. Communications of the ACM, v. 60, n. 10, p. 32-35, 2017.

FACEBOOK. Nubank Brasil. 2017. Disponível em: <https://www.facebook.com/groups/ nubank/>. Acesso em: 04 jan. 2018.

FACEBOOK. Nubank. 2018. Disponível em: <https://www.facebook.com/nubankbrasil/>. Acesso em: 04 jan. 2018.

GOOGLE PLAY. Nubank. 2017. Disponível em: <https://play.google.com/store/apps/ details?id=com.nu.production\&hl=pt_BR>. Acesso em: 04 jan. 2018.

KOZINETS, Robert. Netnography: Doing ethnographic research online. Toronto: Sage Publications, 2010.

KOZINETS, Robert. The field behind the screen: Using netnography for marketing research in online communities. Journal of marketing research, v. 39, n. 1, p. 61-72, 2002.

MINTO, Andrea; VOELKERLING, Moritz; WULFF, Melanie. Separating apples from oranges: identifying threats to financial stability originating from FinTech. Capital markets law journal, v. 12, n. 4, p. 428-465, 2017.

NUBANK. Sobre nós: contrato. 2017. Disponível em: <https://www.nubank.com.br/ contrato>. Acesso em: 05 jan. 2018.

NUBANK. Sobre nós: imprensa. 2017. Disponível em: <https://www.nubank.com.br/ imprensa>. Acesso em: 05 jan. 2018.

NUBANK. Sobre nós: o nu. 2017. Disponível em: 〈https://www.nubank.com.br/sobre-nos〉. Acesso em: 05 jan. 2018.

OSTERWALDER, Alexander. An e-business model ontology for the creation of new management software tools and IS requirement engineering. FIP DsiAge' 2002 doctoral consortium, Cork, Ireland, 2002.

OSTERWALDER, Alexander; PIGNEUR, Yves. Business model generation: inovação em modelos de negócios. Rio de Janeiro: Alta Books, 2011.

OSTERWALDER, Alexander; PIGNEUR, Yves. Value proposition design. United States of America: Wiley Library, 2014.

RICHARDSON, James. The business model: an integrative framework for strategy execution. Strategic change, v. 17, n. 5-6, p. 133-144, 2008. 
TEECE, David. Business models, business strategy and innovation. Long range planning, $v$. 43, n. 2-3, p. 172-194, 2010.

\section{DADOS DOS AUTORES:}

\section{João Paulo Nascimento da Silva}

Currículo Lattes: http://lattes.cnpq.br/9917187297657200

E-mail: jpnsilvas@gmail.com

Mestrando em Administração pela Universidade Federal de Lavras (2017). Mestre em Marketing Relacional pelo Instituto Politécnico de Leiria/PT (2016). MBA em Gestão de Negócios e Empreendimentos pela Universidade Federal de Juiz de Fora (2014). Graduado em Administração de Empresas pelas Faculdades Integradas Vianna Junior (2012). Atualmente é professor na União das Instituições de Serviço, Ensino e Pesquisa, UNISEPE, Faculdade São Lourenço, Brasil.

\section{Álvaro Leonel de Oliveira Castro}

Currículo Lattes: http://lattes.cnpq.br/1670217964335653

E-mail: alvaro.leone193@gmail.com

Mestrando em Administração pela Universidade Federal de Lavras (UFLA). Tecnólogo em Marketing pelo Centro Universitário de Formiga (UNIFOR-MG).

\section{Joel Yutaka Sugano}

Currículo Lattes: http://lattes.cnpq.br/6646670020755884

E-mail: joel.sugano@gmail.com

Pós-doutor pela Wageningen University - The Netherlands. Doutor pelo Doctoral Program in Japanese Economy and Business - Osaka University (2005). Mestre em Administração pela Universidade Federal de Lavras (UFLA). Graduado em Zootecnia pela UFLA. Atualmente é professor da UFLA.

\section{Cledison Carlos de Oliveira}

Currículo Lattes: http://lattes.cnpq.br/5951163691402277

E-mail: oliveira.cledison@gmail.com

Mestrando em administração pela Universidade Federal de Lavras (UFLA). MBA em auditoria empresarial pela Unyleia (2016). Graduado em Ciências Contábeis pelas Faculdades Integradas Adventistas de Minas Gerais (FADMINAS) (2009). 